\title{
CD40 Expression in Human Esophageal Squamous Cell Carcinoma Is Associated with Tumor Progression and Lymph Node Metastasis
}

\author{
YOSHIYUKI MATSUMURA ${ }^{1}$, KEI HIRAOKA ${ }^{1}$, KEIDAI ISHIKAWA ${ }^{1}$, YASUHITO SHOJI ${ }^{1}$, \\ TAKEHIRO NOJI ${ }^{1}$, KOJI HONTANI $^{1}$, TOMOO ITOH $^{2}$, TORU NAKAMURA ${ }^{1}$, \\ TAKAHIRO TSUCHIKAWA ${ }^{1}$, TOSHIAKI SHICHINOHE ${ }^{1}$ and SATOSHI HIRANO ${ }^{1}$ \\ ${ }^{1}$ Department of Gastroenterological Surgery II, Hokkaido University Graduate School of Medicine, Sapporo, Japan; \\ ${ }^{2}$ Department of Pathology, Hokkaido University Hospital, Sapporo, Japan
}

\begin{abstract}
Background: The co-stimulatory molecule cluster of differentiation 40 (CD40) is widely expressed in various types of malignant tumors, but its role remains unclear. The purpose of this study was to investigate the relationship between CD40 expression and clinicopathological variables in patients with esophageal squamous cell carcinoma (ESCC), as well as the function of CD40 expressed on ESCC tumor cells in vitro. Materials and Methods: Tumor specimens of patients who underwent surgical resection for ESCC were immunohistochemically analyzed for CD40 expression. Results: Of the 122 specimens, 45 (37\%) were positive for CD40. Significant positive correlation was found between CD40 expression and p-stage ( $p=0.0011)$, histopathological grade $(p=0.0143), \quad p T$-classification $(p=0.0011)$, and $p N$-classification $(p=0.0007)$. Survival of patients with stage III and IV disease with positive CD40 expression was significantly shorter than that of those with negative expression (log-rank test, $p=0.0422$ ). In in vitro analysis, while the addition of recombinant human CD154 did not inhibit growth, it did induce a significant increase in interleukin 6 production in ESCC cell lines. Conclusion: These results suggest that functional expression of CD40 on tumor cells might play an important role in tumor progression and lymph node metastasis in ESCC.
\end{abstract}

This article is freely accessible online.

Correspondence to: Kei Hiraoka, Department of Gastroenterological Surgery II, Hokkaido University Graduate School of Medicine, Kita 14 Nishi 5, Kita Ku, Sapporo, 060-8638, Japan. Tel: +81117067714, Fax: +81 117067158, e-mail: hiraoka@med hokudai.ac.jp

Key Words: CD40, CD154, CD40 ligand, CD40L, esophageal squamous cell carcinoma, IL6.
Esophageal cancer is the sixth most common cause of cancer deaths in males, with an estimated 455,800 new esophageal cancer cases and 400,200 deaths worldwide reported in 2012 (1). While the number of reported cases in the United States has declined in recent years, the incidence of esophageal cancer is now highest in Eastern Asia and in Eastern and Southern Africa, with $90 \%$ of these cases identified as squamous cell carcinomas (2). Despite significant progress in recent years in preoperative treatments in the neoadjuvant setting followed by radical surgical resection as a standard therapeutic approach for locally advanced esophageal cancer $(3,4)$, prognosis remains poor. Further improvements in survival require new biological parameters that can be used to develop novel therapeutic strategies for esophageal cancer. The co-stimulatory molecule cluster of differentiation 40 (CD40), a member of the tumor necrosis factor receptor superfamily, is predominantly expressed on antigenpresenting cells including B-cells, dendritic cells, and macrophages $(5,6)$. Its ligand CD154 (or CD40L), a 39-kDa membrane glycoprotein, is primarily expressed on activated T-cells. Binding of CD40 to its ligand induces activation and differentiation of B-cells $(7,8)$, the production of various cytokines, and up-regulation of adhesion and co-stimulatory molecules (intercellular adhesion molecule 1, vascular cell adhesion molecule $1, \mathrm{CD} 80$, and CD86) $(6,9,10)$ and plays a crucial role in both humoral and cellular immunity $(5,6)$.

CD40 is also widely expressed on various types of malignant tumors, such as melanoma $(11,12)$, ovarian cancer (13), breast cancer $(14,15)$, non-small cell lung cancer $(16$, 17), colon cancer (18), gastric cancer (19), bladder cancer (20), prostate cancer (21), and renal cell carcinoma (22-25). However, the role of CD40 on tumor cells in malignant progression and in the cancer microenvironment remains unclear. In melanoma (12), bladder (20), gastric (19), and non-small cell lung $(16,17)$ cancer, CD40 expression was demonstrated to be associated with tumor progression and 
poor prognosis. However, the expression of CD40 in esophageal squamous cell carcinoma (ESCC) and its function have not been demonstrated. The purpose of this study was, therefore, to evaluate the expression of CD40 in a cohort of patients with ESCC and to investigate the biological function of CD40 expressed on ESCC cells in vitro.

\section{Materials and Methods}

Cell lines and peripheral blood mononuclear cell isolation. The human esophageal squamous cell carcinoma cell lines TE2, TE4, TE5, TE8, TE9, TE10, TE13, and TE14 were obtained from the Japanese Cell Resource Center for Biomedical Research (Sendai, Japan). HEC46 was provided by Dr. T. Toge (University of Hiroshima, Japan), and SGF7 was provided by Dr. T. Saito (Toyama Medical and Pharmaceutical University, Japan). All cell lines were cultured in RPMI-1640 medium (Sigma-Aldrich, St. Louis, MO, USA) supplemented with $10 \%$ fetal bovine serum (FBS; Thermo Fisher Scientific, Yokomaha, Japan) and 1\% penicillin-streptomycin, and were maintained in a humidified atmosphere with $5 \% \mathrm{CO}_{2}$. Peripheral venous blood samples were obtained from healthy adult donors. Peripheral blood mononuclear cells (PBMCs) were isolated from heparinized blood samples by density gradient centrifugation on Ficoll-paque Plus (GE Healthcare, Uppsala, Sweden), according to the manufacturer's instructions. After centrifugation of the blood samples, the PBMC layer was carefully transferred and the cells were washed three times with phosphate-buffered saline (PBS).

Western blot analysis. Western blot analysis was performed to confirm CD40 expression in ESCC cell lines. Twenty micrograms of cell lysate from each sample was subjected to sodium dodecyl sulfate polyacrylamide gel electrophoresis (SDS-PAGE) using 15\% SDS-polyacrylamide gels, and the protein was transferred to polyvinylidene difluoride membranes (Amersham, Aylesbury, UK). For western blotting, mouse anti-CD40 monoclonal antibody (diluted 1:250; NOVOCASTRA, Newcastle, UK) was used as the primary antibody and the appropriate peroxidase-conjugated goat anti-mouse IgG antibody (1:10,000; Jackson Immuno Research Laboratories, West Grove, PA, USA) was used as the secondary antibody. Chemiluminescent detection of bound antibody was carried out using the ECL system (Amersham). Mouse anti-actin antibody (1:250; EMD Millipore, Darmstadt, Germany) was also used as an internal control. Lysates of normal human PBMCs were used as a positive control for CD40 and lysates of normal human esophageal tissue were used as a negative control.

Cell proliferation assay. Cell proliferation was determined using a tetrazolium dye conversion [2-(2-methoxy-4-nitrophenyl)-3-(4nitrophenyl)-5-(2,4-disulfophenyl)-2H-tetrazolium, monosodium salt (WST-8)] assay (Cell Counting Kit-8; Wako Chemicals, Osaka, Japan). In order to assess cell viability, quadruplicate wells containing $5 \times 10^{3}$ cells per well were cultured in 96-well plates with or without interferon-gamma (IFN $\gamma ; \mathrm{R} \& \mathrm{D}$ systems Inc., Minneapolis, MN, USA) at a final concentration of $100 \mathrm{ng} / \mathrm{ml}$ for 24 hours, and recombinant human soluble CD154 (ALX-582-054KI01; Alexis, Plymouth Meeting, PA, USA) was added at a final concentration of $1000 \mathrm{ng} / \mathrm{ml}$ followed by culture for an additional 48 hours. Dye conversion was measured using an enzyme-linked immunosorbent assay (ELISA) plate reader (Molecular Devices,
Tokyo, Japan) at wavelengths of $450 \mathrm{~nm}$ and $600 \mathrm{~nm}$ after $2 \mathrm{~h}$ incubation at $37^{\circ} \mathrm{C}$. Cell proliferation was determined by calculation of the absorbance of viable cells as measured against control wells containing PBS alone.

ELISA measurement of IL6. To measure IL6 levels in cell culture supernatants, triplicate wells containing TE10, HEC46, or SGF7 cells $\left(2 \times 10^{5}\right.$ cells per well) were cultured in 24 -well plates with IFN $\gamma(100 \mathrm{ng} / \mathrm{ml})$ for $24 \mathrm{~h}$ and the cells were then stimulated with PBS or recombinant human soluble CD154 (rhCD154) at a final concentration of $1,000 \mathrm{ng} / \mathrm{ml}$. After additional culture for $48 \mathrm{~h}$, the supernatants were harvested and the concentration of IL6 was measured using the commercially available Human IL-6 Quantikine Enzyme Linked Immunosorbent assay (ELISA) kit (R\&D Systems Inc.), according to the manufacturer's instructions. The final concentration of IL6 was normalized to the cell number.

Flow cytometric analysis of surface CD40 expression. The expression of CD40 on the surface of ESCC cells was examined using flow cytometric analysis. Briefly, $4 \times 10^{5}$ cells were seeded into 12-well plates and cultured with or without recombinant human IFN $\gamma(100 \mathrm{ng} / \mathrm{ml})$ for $48 \mathrm{~h}$. The cells were then trypsinized with 1 $\mathrm{ml}$ of $0.25 \%$ trypsin for 10 minutes, washed with PBS, and resuspended in $100 \mu \mathrm{l}$ of PBS supplemented with $2 \%$ fetal bovine serum. The cell suspension was incubated on ice for $30 \mathrm{~min}$ with a fluorescein isothiocyanate (FITC)-conjugated anti-CD40 monoclonal antibody (555588; BD Biosciences, San Jose, CA, USA). In parallel, FITC-conjugated mouse IgG1K (554679; BD Biosciences) served as an isotype control. The expression of CD40 was then analyzed using CellQuest software (BD Biosciences). PBMCs were included as a positive control.

Patients and specimens. This study was conducted at the Hokkaido University in accordance with Institutional Review Board guidelines. One hundred and twenty-two patients (105 men and 17 women; mean age, 62.3 years) with primary ESCC underwent radical esophagectomy between September 1989 and May 1999 at the Department of Surgical Oncology, School of Medicine, Hokkaido University, or at two affiliated hospitals. No distant metastasis was detected in any patient upon preoperative examination. No patient had received prior anticancer treatment. Cases of in-hospital death were excluded from the current study. The clinical typing of tumors was determined according to the TNM classification system of the International Union Against Cancer (26). All specimens were fixed in $10 \%$ formalin and embedded in paraffin wax. One of the deepest sections from each tumor was selected for evaluation, and serial $4-\mu$ m-thick sections were examined using immunohistochemistry.

Immunohistochemical examination. Immunohistochemical reactions were performed using the universal immuno-enzyme polymer method. Sections were deparaffinized in xylene, dehydrated through a graded ethanol series, and placed in a plastic container containing EDTA buffer ( $\mathrm{pH}$ 8.0). After heating in a pressure cooker for $2 \mathrm{~min}$ at the highest pressure, the sections were cooled and endogenous peroxidase activity was blocked by incubation in $0.3 \%$ hydrogen peroxide in methanol for 10 minutes. The sections were washed three times in PBS containing 1\% Tween 20, followed by incubation in $10 \%$ normal goat serum (Nichirei Cooperation, Tokyo, Japan) for 30 min. Anti-human CD40 mouse monoclonal antibody (11E9; 
Novocastra, Newcastle, UK), was applied at 1:40 dilution and specimens were then incubated individually overnight at $4^{\circ} \mathrm{C}$. After three additional washes with PBS, sections were incubated with a biotinylated goat antibody to mouse immunoglobulin [Histofine Simple Stain MAX-PO (MULTI); Nichirei Cooperation] for $30 \mathrm{~min}$ at room temperature. Sections were washed with PBS, and the immunohistochemical reactions were visualized by incubation for approximately $5 \mathrm{~min}$ with 3-3'-diaminobenzidine tetrahydrochloride (Histofine Simple Stain DAB Solution; Nichirei Cooperation), followed by washing in distilled water. Sections were counterstained in hematoxylin for 1 minute and were then mounted in Permount (Micro Slide; Muto-Glass, Tokyo, Japan). Normal human lymph nodes were used as a positive tissue control for CD40. The negative reagent control for CD40 consisted of serial tissue sections of each sample in which isotype-matched negative control mouse IgG (IgG2b: X0944, Dako, Tokyo, Japan) was used as a primary antibody.

Classification of CD40 staining in ESCC. We selected sections that contained the deepest site for each tumor, and these immunostained sections were evaluated under a microscope (Olympus Optical Co., Ltd., Tokyo, Japan). The degree of staining was counted in more than 10 independent high-power microscopic fields $(\times 400)$ for each tissue sample. The five areas containing the highest density of reactive cells were evaluated in each case, and the mean percentage of cancer cells with positive staining for CD40 was determined. Tissue sections with fewer than four reactive tumor cells per high power field (HPF) were considered CD40-negative and those with four or more reactive cells HPF were defined as CD40-positive. Three investigators of our study (Y.M., K.I., and T.I.) independently evaluated the immunohistochemical labeling of all specimens, without knowledge of patient background or outcome. Immunoreactivity in each section was represented by the median scores evaluated by the three independent investigators.

Statistical analysis. For correlations between CD40 status and patients' clinicopathological variables, statistical significance was evaluated by the $\chi^{2}$ test and Fisher's exact test. For the IL6 ELISA, the comparison of two groups was performed using Student's $t$-test. The cumulative survival rate was calculated using the Kaplan-Meier method. Statistical significance was analyzed by the log-rank test. Overall survival rates were calculated using the period from surgery to death Probability values of less than 0.05 were considered statistically significant in all of the analyses. All analyses were performed with statistical software (Prism 6; Graphpad, La Jolla, CA, USA).

\section{Results}

CD40 expression in human ESCC. CD40 expression was immunohistochemically analyzed in 122 ESCC specimens. Representative photomicrographs of positive and negative immunohistochemical staining for CD40 are shown in Figure 1. Each specimen contained lymphocytes that stained for CD40, which served as internal positive controls (Figure 1A). Within the tumor, the distribution of CD40 staining was heterogeneous, and CD40 immunoreactivity was detected both in the cytoplasm and on the plasma membranes of cancer cells (Figure 1B); no reactivity was observed in normal esophageal mucosa (Figure 1C). For the microscopic

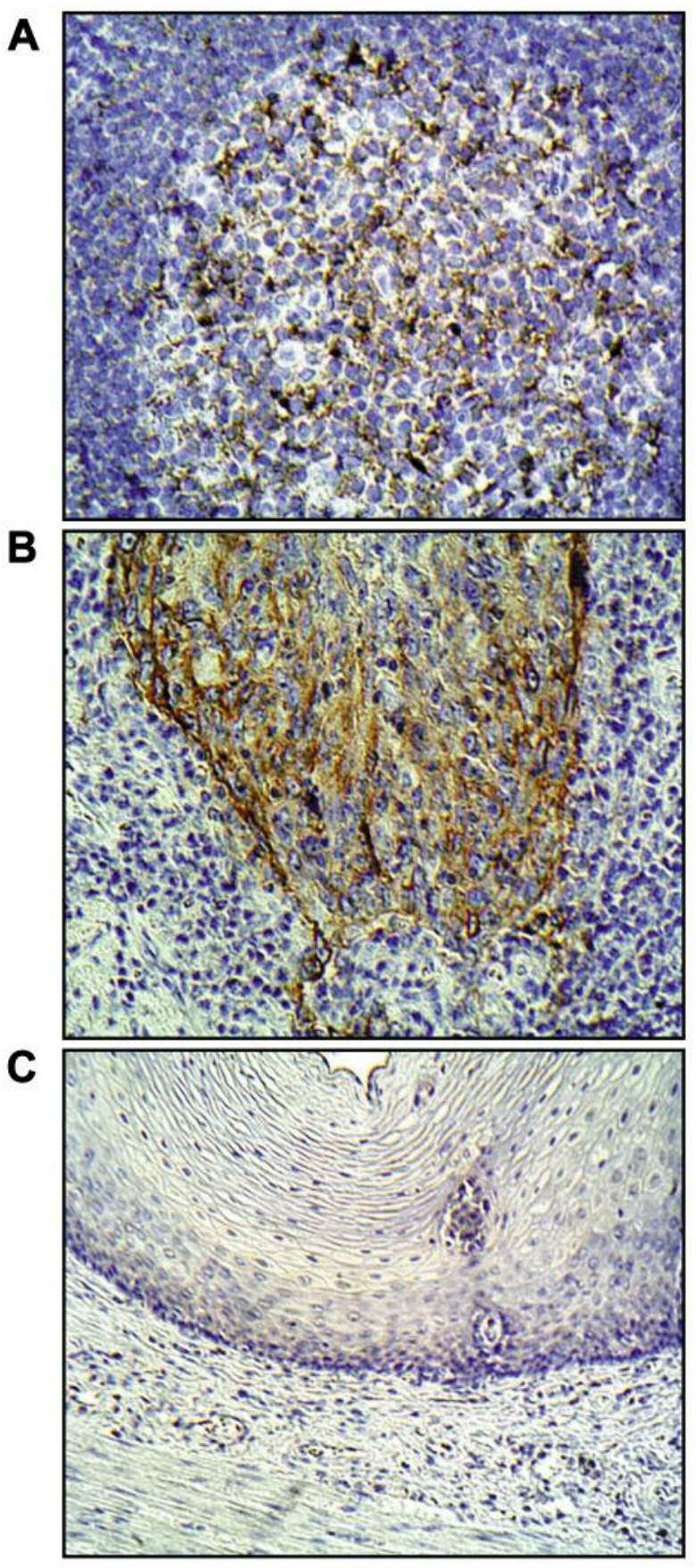

Figure 1. Representative immunohistochemical staining of surgical specimens for CD40. A: Positive expression of CD40 in a normal lymph node served as a positive control. B: Positive expression of CD40 in the cell membranes and cytoplasm of esophageal squamous cell carcinoma cells (original magnification, $\times 400$ ). C: Negative expression of CD40 in normal esophageal mucosa. Original magnification, $\times 200$.

classification of CD40 expression on tumor cells, the morphological findings of each cell were carefully evaluated to minimize the risk of including CD40-positive monocytes, 

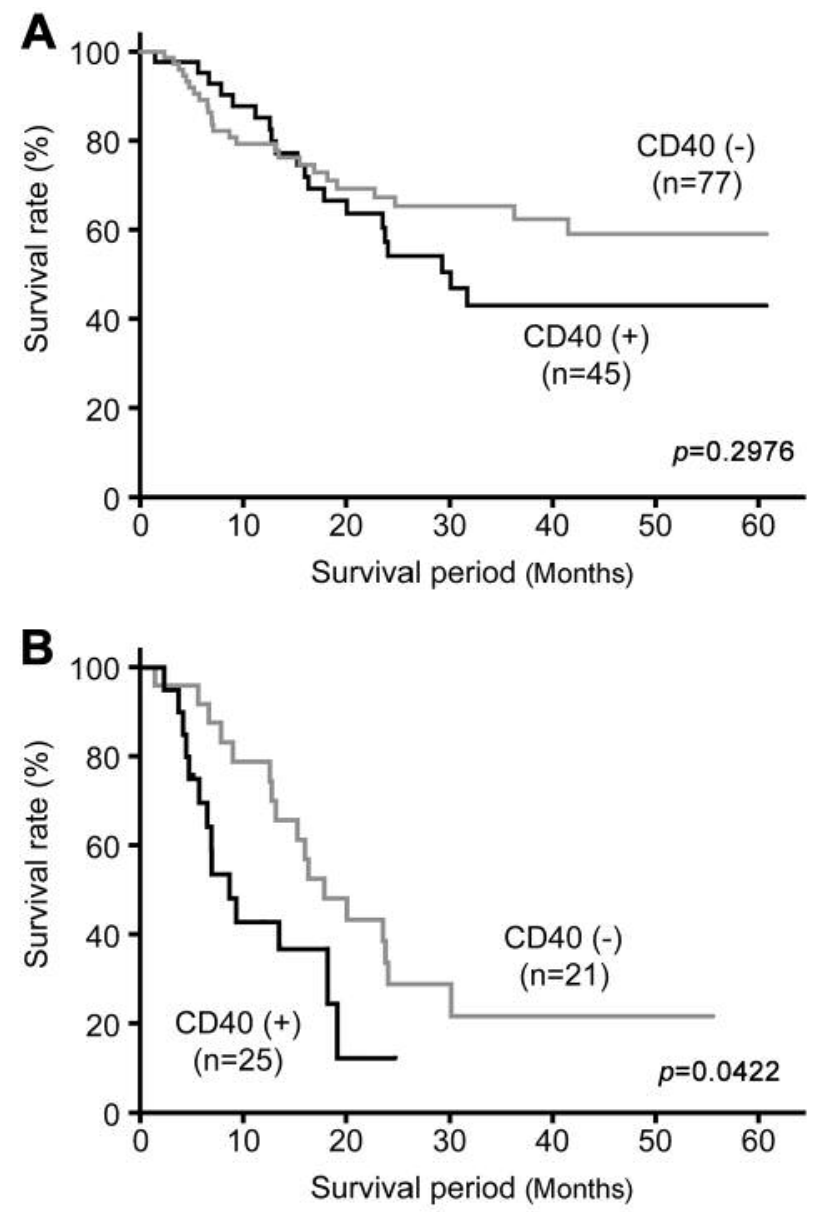

Figure 2. Kaplan-Meier analysis for overall survival according to CD40 expression in patients with all stages of esophageal squamous cell carcinoma (ESCC) (A) in patients with stage III and IV ESCC (B).

as previously described $(17,25,27)$. Based on this analysis, CD40 expression was defined as positive in 45 cases $(36.9 \%)$ and negative in 77 cases $(63.1 \%)$.

Correlation between CD40 status and clinicopathological variables. Correlations between the status of CD40 expression and clinicopathological features in ESCC are summarized in Table I. There were no significant correlations with age, gender, or M-classification. CD40 status was significantly positively correlated with pStage $(p=0.0011)$, histopathological grade $(p=0.0143)$, pTclassification $(p=0.0011)$, and $\mathrm{pN}$-classification $(p=0.0007)$.

Kaplan-Meier survival analysis. Survival curves according to CD40 expression were constructed according to the Kaplan-Meier method (Figure 2). Among 122 patients with ESCC, the survival rates for patients positive for CD40 expression were lower than for those negative for CD40
Table I. Association between CD40 expression and clinicopathological variables in patients with esophageal squamous cell carcinoma.

\begin{tabular}{|c|c|c|c|c|}
\hline \multirow[t]{2}{*}{ Variables } & \multirow{2}{*}{$\begin{array}{l}\text { Number } \\
\text { of cases }\end{array}$} & \multicolumn{2}{|c|}{$\mathrm{CD} 40$} & \multirow[t]{2}{*}{$p$-Value } \\
\hline & & $\begin{array}{c}\text { Positive } \\
(\mathrm{n}=45)\end{array}$ & $\begin{array}{c}\text { Negative } \\
(\mathrm{n}=77)\end{array}$ & \\
\hline \multicolumn{5}{|l|}{ Gender } \\
\hline Male & 105 & 42 & 63 & \multirow[t]{2}{*}{0.1045} \\
\hline Female & 17 & 3 & 14 & \\
\hline \multicolumn{5}{|l|}{ Age, years } \\
\hline$\geq 60$ & 79 & 34 & 45 & \multirow[t]{2}{*}{0.0768} \\
\hline$<60$ & 43 & 11 & 32 & \\
\hline \multicolumn{5}{|l|}{ pStage } \\
\hline I & 38 & 5 & 33 & \multirow[t]{4}{*}{$0.0011^{*}$} \\
\hline II & 38 & 15 & 23 & \\
\hline III & 27 & 16 & 11 & \\
\hline IV & 19 & 9 & 10 & \\
\hline \multicolumn{5}{|c|}{ Histopathological grade } \\
\hline G1 & 32 & 5 & 27 & \multirow[t]{3}{*}{$0.0143 *$} \\
\hline $\mathrm{G} 2$ & 62 & 27 & 35 & \\
\hline G3 & 28 & 13 & 15 & \\
\hline \multicolumn{5}{|c|}{ pT classification } \\
\hline $\mathrm{T} 1$ & 54 & 10 & 44 & \multirow[t]{4}{*}{$0.0011 *$} \\
\hline $\mathrm{T} 2$ & 13 & 7 & 6 & \\
\hline $\mathrm{T} 3$ & 43 & 24 & 19 & \\
\hline $\mathrm{T} 4$ & 12 & 4 & 8 & \\
\hline \multicolumn{5}{|c|}{$\mathrm{pN}$ classification } \\
\hline N1 & 60 & 13 & 47 & \multirow[t]{2}{*}{$0.0007 *$} \\
\hline $\mathrm{N} 2$ & 62 & 32 & 30 & \\
\hline \multicolumn{5}{|c|}{ pM classification } \\
\hline M0 & 101 & 35 & 66 & \multirow[t]{2}{*}{0.3220} \\
\hline M1 & 21 & 10 & 11 & \\
\hline
\end{tabular}

*Significantly different.

expression, but the difference was not statistically significant (log-rank test, $p=0.2976$; Figure 2A). In selected cases with stage III and IV disease $(n=46)$, the survival rates for patients positive for CD40 expression were significantly lower than for those negative for CD40 expression (log-rank test, $p=0.0422$; Figure 2B), suggesting that CD40 expression might be associated with poor prognosis of patients with advanced ESCC.

CD40 expression in human ESCC cell lines. In order to examine the biological function of CD40 expressed in ESCC cells, we first evaluated ESCC cell lines for CD40 expression in vitro. Of the 11 ESCC cell lines tested, TE5, TE10, and HEC46 were positive for CD40 expression $(>1.0 \%)$ by flow-cytometric analysis (Figure 3A). This finding was confirmed by western blot analysis in which TE5, TE10, and HEC46 showed high levels of a 42-kDa protein that cross-reacted with the anti-CD40 antibody 
A

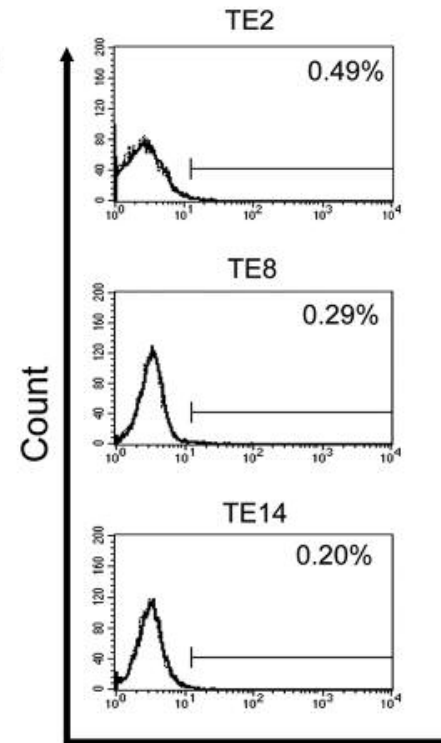

TE4

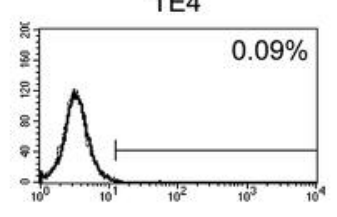

TE9

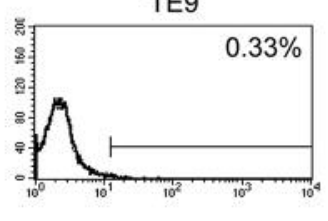

HEC46

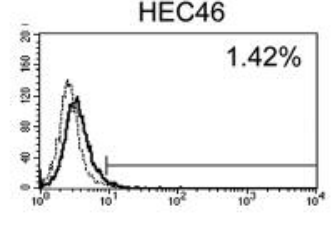

TE5

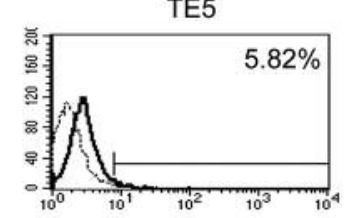

TE10
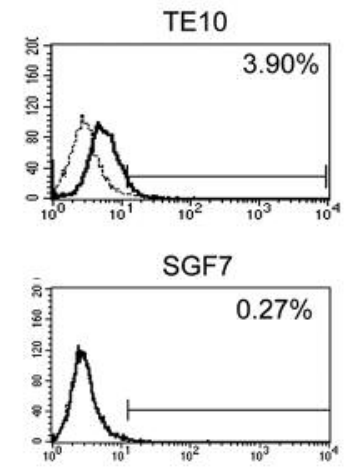

TE6

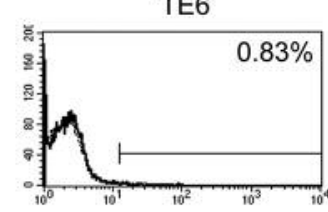

TE13

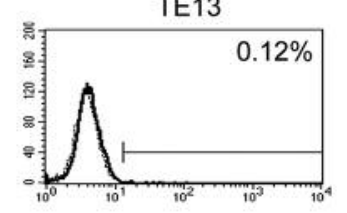

PBMCs

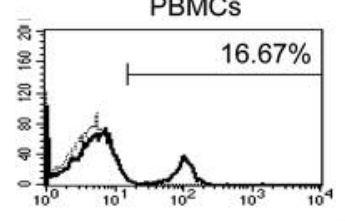

CD40

B

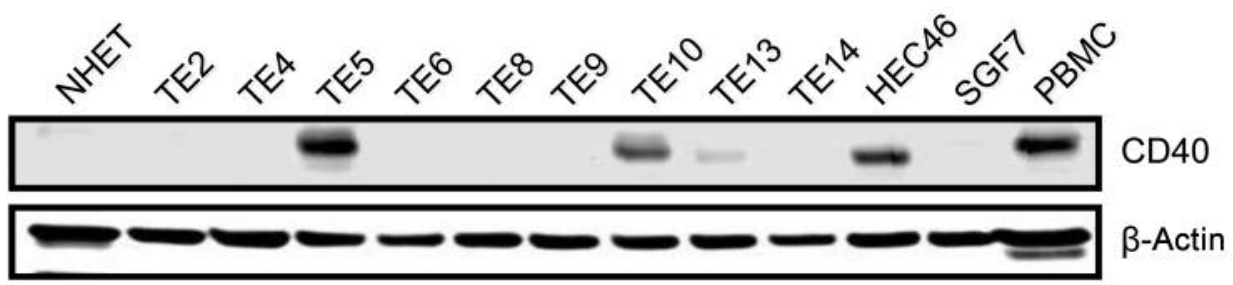

Figure 3. CD40 expression in esophageal squamous cell carcinoma (ESCC) cell lines. A: The level of cell surface CD40 expression on each ESCC cell line was analyzed using fluorescein isothiocyanate conjugated anti-CD40 monoclonal antibody (black) and flow cytometry. Background staining is indicated in grey. B: Western blots of cell lysates were probed with an anti-human CD40 antibody, or anti- $\beta$-actin antibody as an internal control. A lysate from normal human peripheral blood mononuclear cells (PBMC) was used as a positive control and a lysate from normal human esophageal tissue (NHET) was used as a negative control.

compared to the other ESCC cell lines (Figure 3B). In addition, treatment of CD40-positive cell lines with IFN $\gamma$ resulted in an increase in cell-surface CD40 expression as assessed by flow-cytometric analysis (Figure 4).

Effects of recombinant CD154 on ESCC cells in vitro. As CD40 interacts with CD154 to regulate its signaling pathways, in vitro proliferation was then examined by the WST-8 assay following exposure of two CD40-positive (TE10, HEC46) and one CD40-negative (SGF7) ESCC cell lines to rhCD154 with and without IFN $\gamma$ stimulation (Figure 5). IFN $\gamma$ stimulation resulted in significant growth suppression of the CD40-positive cell lines, however, rhCD154 stimulation had no significant growth-inhibitory effect on any cell line.

In order to evaluate the association between CD40 signaling and cytokine production in ESCC, the culture supernatants from cells were examined for IL6 by ELISA
(Figure 6). IL6 production was significantly increased in all three cell lines following IFN $\gamma$ stimulation. Furthermore, an additive increase in IL6 secretion was observed when cells were treated with rhCD154 in combination with IFN $\gamma$, even in SGF7 cell line with low CD40 expression.

\section{Discussion}

In the present study, out of the 122 surgically resected ESCC, 45 cases $(37 \%)$ were classified as positive for CD40 expression. This incidence of CD40 expression was similar to that reported for other cancer types. Previous immunohistochemical studies reported CD40 expression in $69.2 \%$ of pancreatic adenocarcinomas (28), and in $51.9 \%$ of non-small cell lung cancer cases (17). We also found that patients with tumors that were classified as positive for CD40 expression had a more advanced pathological stage, poorer differentiation, higher frequency of positive lymph 
node metastasis, and a more extensive tumor. These correlations suggest that CD40 expression in the tumor itself might up-regulate tumor progression and metastatic potential in ESCC. In clinical analysis of human lung cancer, it has been reported that positive CD40 expression in tumors showed a significant correlation with metastatic spread (12). By binding with its ligand CD154, CD40 expressed on the endothelial cell surface was shown to up-regulate the production of cytokines and chemokines, and also to increase the expression of co-stimulatory and adhesion molecules and the production of matrix metalloproteinases $(6,10,29)$. Likewise, in ESCC, our results of activation of the CD40 pathway by CD154 or IFN $\gamma$, based on induction of IL6 production, suggest that these other factors may also be increased following stimulation and may allow cancer cells to spread to the regional lymph nodes.

The prognostic significance of CD40 expression in tumors depends on the cell type and remains controversial. In terms of survival, we found that patients with CD40-positive tumors had a shorter survival compared to patients with CD40-negative tumors, although the difference between them was not statistically significant. However when cases with stage III and IV disease were selected, the overall 5year survival rate for patients with positive CD40 expression (12.2\%) was significantly lower than for those with negative expression $(21.7 \%)$. Our data are consistent with a number of previous reports of other tumor types. Thus, a correlation between CD40 expression on tumor cells and poor prognosis has been reported in melanoma (12), bladder cancer (20), gastric cancer (19), and lung cancer $(16,17)$. However, in contrast, positive CD40 expression was associated with better survival in patients with renal cell carcinoma (25). The reason for this discrepancy remains unclear.

In order to identify the role of the CD40 signaling pathway in ESCC, we evaluated whether CD40 signaling correlated with cancer cell growth of ESCC in vitro. In the ESCC cell lines tested, we found that CD40 stimulation mediated by rhCD154 ligation did not inhibit growth in a cell proliferation assay. This result is in contrast to previous reports of a direct anti-proliferative effect induced by CD40-CD154 interaction in various cancer cells in vitro or in vivo $(30,31)$. On the other hand, recent studies demonstrated that stimulation of CD40 protects human bladder carcinoma cells from apoptosis (32), and that a low level of CD40 expression on tumor cells was not associated with cell growth in head and neck squamous cell cancer and ovarian cancer $(27,33)$. Thus, the effect of CD40 on tumor proliferation differs depending on the cancer type, and in ESCC, a direct anti-proliferative effect of CD40 may not be evident due to the low level of CD40 expression in the ESCC cell lines (less than 20\%).

In addition to exerting a direct anti-proliferative effect on tumor cells, previous studies have demonstrated a role for CD40 in immunosuppression within the tumor micro-
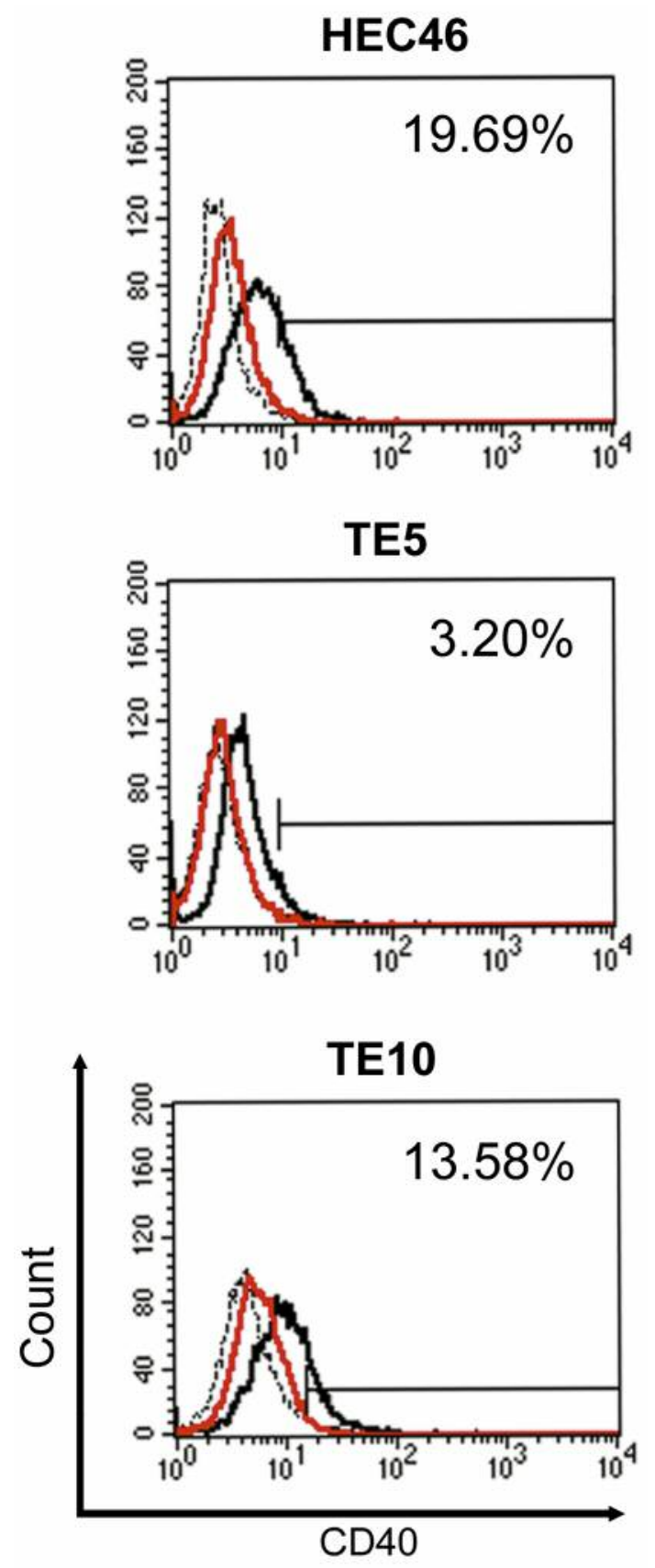

Figure 4. Interferon gamma (IFN $\gamma$ ) stimulation increased cell surface CD40 expression in esophageal squamous cell carcinoma cell lines. Cell surface CD40 was analyzed using flow cytometry of the indicated cell lines following treatment with (black line) or without (red line) IFN $\gamma(100 \mathrm{ng} / \mathrm{ml})$. IFN $\gamma$-treated cells stained with isotype control IgG are indicated with a broken line.

environment. In CD40-positive tumors, CD40 reportedly suppressed immune responses through down-regulation of CD154 and inactivated T-cell responses (34). Furthermore, direct interaction between the CD40 expressed on tumor cells 

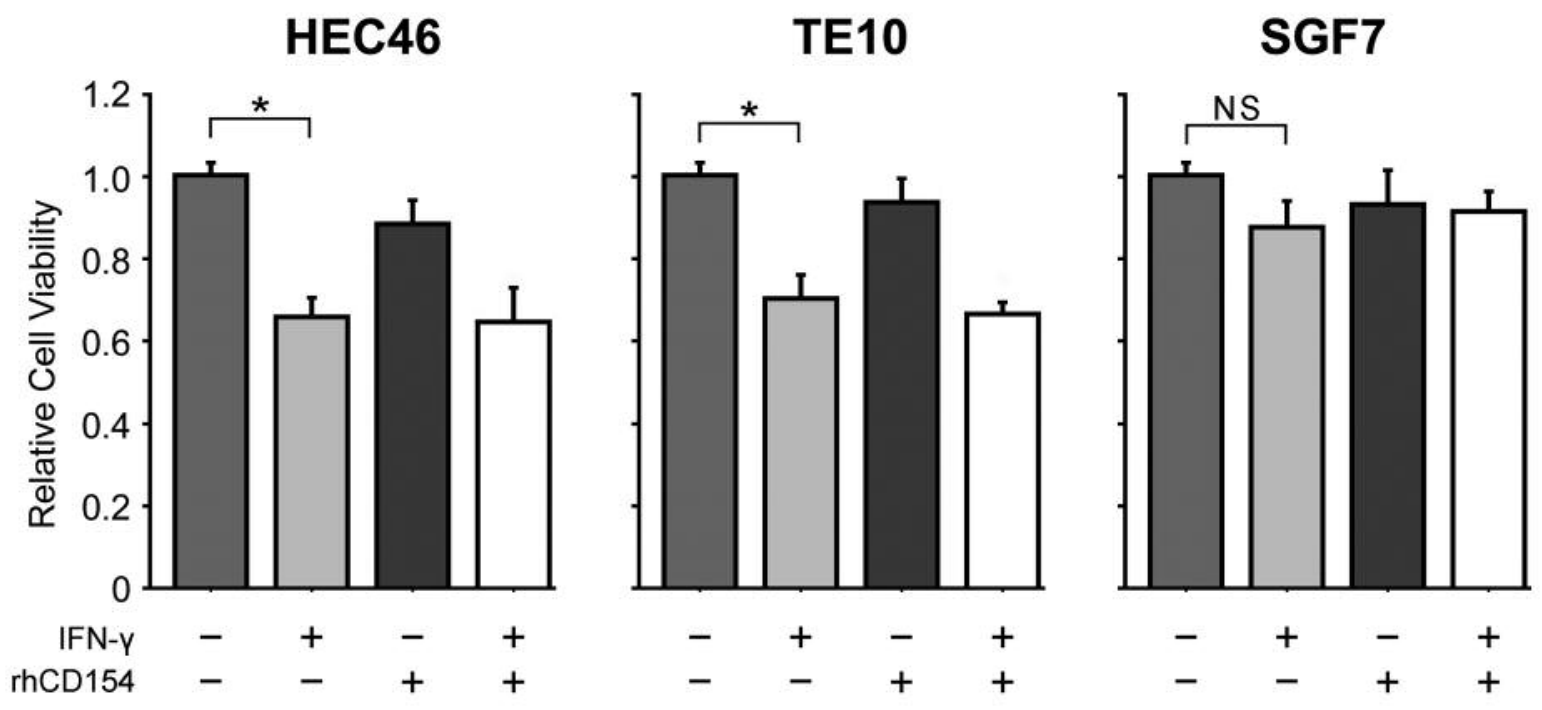

Figure 5. Effect of soluble recombinant human CD154 (rhCD154) treatment combined with interferon gamma (IFN $\gamma$ ) stimulation on esophageal squamous cell carcinoma cell proliferation. The proliferation of HEC46, TE10 and SGF7 cell lines was assessed following addition of IFN $\gamma$ (100 $\mathrm{ng} / \mathrm{ml})$ on day 1 with/without rhCD154 $(1,000 \mu \mathrm{g} / \mathrm{ml})$ on day 2 as indicated. Cell proliferation was determined by calculation of the absorbance of viable cells as measured against control wells containing phosphate buffered saline alone. ${ }^{*} p<0.05$; NS: not significant, $p \geq 0.05$.

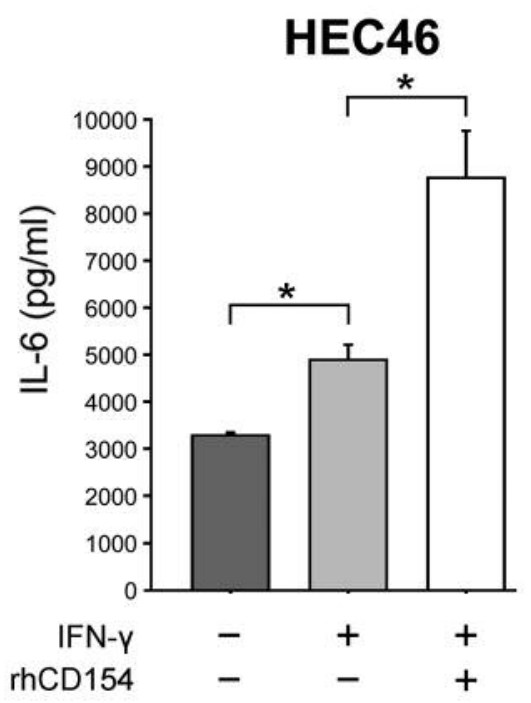

TE10

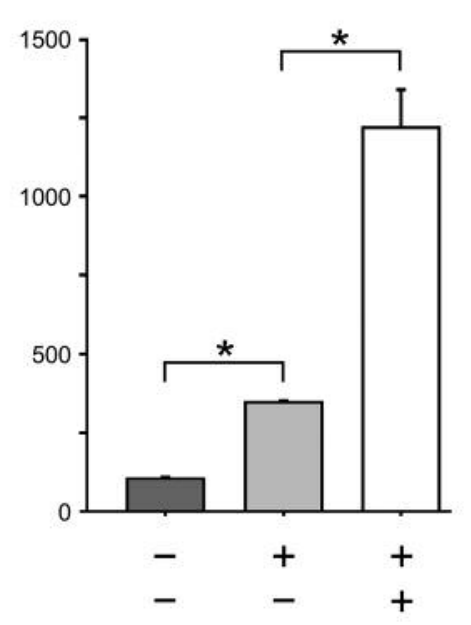

SGF7

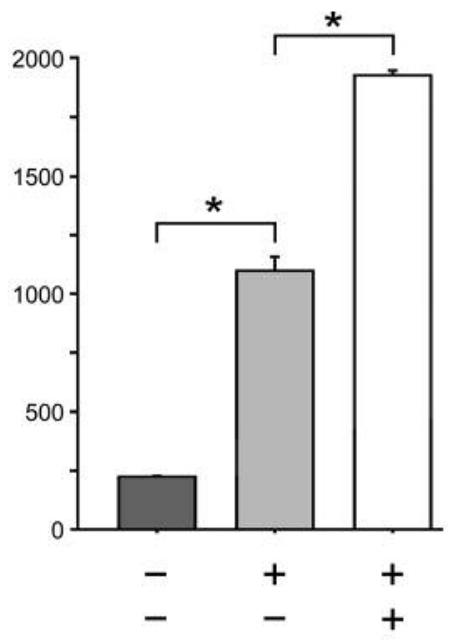

Figure 6. Interleukin 6 (IL6) secretion following stimulation of esophageal squamous cell carcinoma cell lines with recombinant human CD154 (rhCD154) with/without interferon gamma (IFN $\gamma)$. * $p<0.05$.

and CD154 on activated T-cells increased TGF $\beta$ production and the differentiation of Th17 cells, resulting in acceleration of cancer cell proliferation (35). These findings strongly indicate that CD40 expression might work in favor of cancer progression and immuno-evasion mechanisms in the cancer microenvironment. In the present study, a significant increase in IL6 production was induced by rhCD154 in ESCC cell lines, even in the cell line with low CD40 expression. Previous studies have demonstrated that CD40 induces the up-regulation of IL6 production in various tumors including multiple myeloma (36), breast cancer (35), ovarian carcinoma (33), and non-small cell lung cancer (37). Furthermore, IL6 has been reported to induce tumor progression in various human malignancies, including esophageal cancer (38). In ESCC, IL6 
has been significantly associated with poor prognosis (39), and acts as an autocrine anti-apoptotic growth factor to support tumor progression (40). These previous findings regarding CD40 and IL6 support the idea that IL6 may play an important role as one of the central factors in CD40-mediated tumor progression in ESCC.

To our knowledge, this is the first study to show the expression of functional CD40 on ESCC cells, and our results suggest that the high incidence of CD40 expression is associated with tumor differentiation, extent of the tumor, and lymph node metastasis in ESCC. Combined with previous findings that show immunosuppressive functions of CD40 signaling in cancer progression, these data suggest that it may be possible to re-activate immunoresponsiveness against ESCC by using potential immunotherapeutic tools such as an antiCD40 antagonistic antibody or by silencing CD40 expression.

\section{Acknowledgements}

The Authors are grateful to Hikaru Shida and Naomi Saito for their technical support in the immunohistochemical analyses, as well as to the physicians who cared for these patients at affiliated hospitals of Hokkaido University. They also dedicate this article to Dr. Masaki Miyamoto in appreciation of his generous support. This work was supported by a Grant-in-Aid for Scientific Research from the Ministry of Education, Culture, Sports, Science and Technology of Japan.

\section{Disclosure Statement}

All Authors declare no competing financial interests.

\section{References}

1 Torre LA, Bray F, Siegel RL, Ferlay J, Lortet-Tieulent J and Jemal A: Global cancer statistics, 2012. CA Cancer J Clin 65: 87-108, 2015.

2 Pohl H, Sirovich B and Welch HG: Esophageal adenocarcinoma incidence: are we reaching the peak? Cancer Epidemiol Biomarkers Prev 19: 1468-1470, 2010.

3 Ando N, Kato H, Igaki H, Shinoda M, Ozawa S, Shimizu H, Nakamura T, Yabusaki H, Aoyama N, Kurita A, Ikeda K, Kanda T, Tsujinaka T, Nakamura $\mathrm{K}$ and Fukuda $\mathrm{H}$ : A randomized trial comparing postoperative adjuvant chemotherapy with cisplatin and 5-fluorouracil versus preoperative chemotherapy for localized advanced squamous cell carcinoma of the thoracic esophagus (JCOG9907). Ann Surg Oncol 19: 68-74, 2012.

4 van Hagen P, Hulshof MC, van Lanschot JJ, Steyerberg EW, van Berge Henegouwen MI, Wijnhoven BP, Richel DJ, Nieuwenhuijzen GA, Hospers GA, Bonenkamp JJ, Cuesta MA, Blaisse RJ, Busch OR, ten Kate FJ, Creemers GJ, Punt CJ, Plukker JT, Verheul HM, Spillenaar Bilgen EJ, van Dekken H, van der Sangen MJ, Rozema T, Biermann K, Beukema JC, Piet AH, van Rij CM, Reinders JG, Tilanus HW, van der Gaast A and Group C: Preoperative chemoradiotherapy for esophageal or junctional cancer. N Engl J Med 366: 2074-2084, 2012.

5 Grewal IS and Flavell RA: CD40 and CD154 in cell-mediated immunity. Annu Rev Immunol 16: 111-135, 1998.
6 van Kooten C and Banchereau J: CD40-CD40 ligand. J Leukoc Biol 67: 2-17, 2000.

7 Armitage RJ, Fanslow WC, Strockbine L, Sato TA, Clifford KN, Macduff BM, anderson DM, Gimpel SD, Davis-Smith T, Maliszewski CR et al: Molecular and biological characterization of a murine ligand for CD40. Nature 357: 80-82, 1992.

8 Bishop GA and Hostager BS: Signaling by CD40 and its mimics in B cell activation. Immunol Res 24: 97-109, 2001.

9 Schulz O, Edwards AD, Schito M, Aliberti J, Manickasingham S, Sher A and Reis e Sousa C: CD40 triggering of heterodimeric IL-12 p70 production by dendritic cells in vivo requires a microbial priming signal. Immunity 13: 453-462, 2000.

10 Grammer AC and Lipsky PE: CD40-mediated regulation of immune responses by TRAF-dependent and TRAF-independent signaling mechanisms. Adv Immunol 76: 61-178, 2000.

11 von Leoprechting A, van der Bruggen P, Pahl HL, Aruffo A and Simon JC: Stimulation of CD40 on immunogenic human malignant melanomas augments their cytotoxic $\mathrm{T}$ lymphocyte-mediated lysis and induces apoptosis. Cancer Res 59: 1287-1294, 1999.

12 van den Oord JJ, Maes A, Stas M, Nuyts J, Battocchio S, Kasran A, Garmyn M, De Wever I and De Wolf-Peeters C: CD40 is a prognostic marker in primary cutaneous malignant melanoma. Am J Pathol 149: 1953-1961, 1996.

13 Hakkarainen T, Hemminki A, Pereboev AV, Barker SD, Asiedu CK, Strong TV, Kanerva A, Wahlfors J and Curiel DT: CD40 is expressed on ovarian cancer cells and can be utilized for targeting adenoviruses. Clin Cancer Res 9: 619-624, 2003.

14 Wingett DG, Vestal RE, Forcier K, Hadjokas N and Nielson CP: CD40 is functionally expressed on human breast carcinomas: variable inducibility by cytokines and enhancement of Fasmediated apoptosis. Breast Cancer Res Treat 50: 27-36, 1998.

15 Tong AW, Papayoti MH, Netto G, Armstrong DT, Ordonez G, Lawson JM and Stone MJ: Growth-inhibitory effects of CD40 ligand (CD154) and its endogenous expression in human breast cancer. Clin Cancer Res 7: 691-703, 2001.

16 Sabel MS, Yamada M, Kawaguchi Y, Chen FA, Takita H and Bankert RB: CD40 expression on human lung cancer correlates with metastatic spread. Cancer Immunol Immunother 49: 101$108,2000$.

17 Ishikawa K, Miyamoto M, Yoshioka T, Kato T, Kaji M, Ohbuchi T, Hirano S, Itoh T, Dosaka-Akita H and Kondo S: Up-regulation of CD40 with juxtacrine activity in human nonsmall lung cancer cells correlates with poor prognosis. Cancer 113: 530-541, 2008.

$18 \mathrm{Wu}$ Y, Wang L, He X, Xu H, Zhou L, Zhao F and Zhang Y: Expression of CD40 and growth-inhibitory activity of CD40 ligand in colon cancer ex vivo. Cell Immunol 253: 102-109, 2008.

$19 \mathrm{Li} \mathrm{R}$, Chen WC, Pang XQ, Hua C, Li L and Zhang XG: Expression of CD40 and CD40L in gastric cancer tissue and its clinical significance. Int J Mol Sci 10: 3900-3917, 2009.

20 Cooke PW, James ND, Ganesan R, Wallace M, Burton A and Young LS: CD40 expression in bladder cancer. J Pathol 188: 3843, 1999.

21 Rokhlin OW, Bishop GA, Hostager BS, Waldschmidt TJ, Sidorenko SP, Pavloff N, Kiefer MC, Umansky SR, Glover RA and Cohen MB: Fas-mediated apoptosis in human prostatic carcinoma cell lines. Cancer Res 57: 1758-1768, 1997.

22 Kluth B, Hess S, Engelmann H, Schafnitzel S, Riethmuller G and Feucht HE: Endothelial expression of CD40 in renal cell carcinoma. Cancer Res 57: 891-899, 1997. 
23 Bussolati B, Russo S, Deambrosis I, Cantaluppi V, Volpe A, Ferrando U and Camussi G: Expression of CD154 on renal cell carcinomas and effect on cell proliferation, motility and plateletactivating factor synthesis. Int J Cancer 100: 654-661, 2002.

24 Shorts L, Weiss JM, Lee JK, Welniak LA, Subleski J, Back T, Murphy WJ and Wiltrout RH: Stimulation through CD40 on mouse and human renal cell carcinomas triggers cytokine production, leukocyte recruitment and antitumor responses that can be independent of host CD40 expression. J Immunol 176: 6543-6552, 2006.

25 Weiss JM, Gregory Alvord W, Quinones OA, Stauffer JK and Wiltrout RH: CD40 expression in renal cell carcinoma is associated with tumor apoptosis, CD8(+) T cell frequency and patient survival. Hum Immunol 75: 614-620, 2014.

26 Sobin LH, Gospodarowicz MK and Wittekind C: TNM Classification of Malignant Tumours, 7th edition. Chichester: Wiley-Blackwell, 2009.

27 Posner MR, Cavacini LA, Upton MP, Tillman KC, Gornstein ER and Norris CM, Jr.: Surface membrane-expressed CD40 is present on tumor cells from squamous cell cancer of the head and neck in vitro and in vivo and regulates cell growth in tumor cell lines. Clin Cancer Res 5: 2261-2270, 1999.

$28 \mathrm{He} \mathrm{S}$, Zhao H, Fei M, Wu Y, Wang L, Zhu X and Li D: Expression of the co-signaling molecules CD40-CD40L and their growth-inhibitory effect on pancreatic cancer in vitro. Oncol Rep 28: 262-268, 2012.

29 Henn V, Slupsky JR, Grafe M, Anagnostopoulos I, Forster R, Muller-Berghaus G and Kroczek RA: CD40 ligand on activated platelets triggers an inflammatory reaction of endothelial cells. Nature 391: 591-594, 1998.

30 Eliopoulos AG, Davies C, Knox PG, Gallagher NJ, Afford SC, Adams DH and Young LS: CD40 induces apoptosis in carcinoma cells through activation of cytotoxic ligands of the tumor necrosis factor superfamily. Mol Cell Biol 20: 5503-5515, 2000

31 Gallagher NJ, Eliopoulos AG, Agathangelo A, Oates J, Crocker $\mathrm{J}$ and Young LS: CD40 activation in epithelial ovarian carcinoma cells modulates growth, apoptosis and cytokine secretion. Mol Pathol 55: 110-120, 2002.

32 Jakobson E, Jonsson G, Bjorck P and Paulie S: Stimulation of CD40 in human bladder carcinoma cells inhibits anti-Fas/APO1 (CD95)-induced apoptosis. Int J Cancer 77: 849-853, 1998.

33 Toutirais O, Gervais A, Cabillic F, Le Gallo M, Coudrais A, Leveque J, Catros-Quemener V and Genetet N: Effects of CD40 binding on ovarian carcinoma cell growth and cytokine production in vitro. Clin Exp Immunol 149: 372-377, 2007.
34 Batrla R, Linnebacher M, Rudy W, Stumm S, Wallwiener D and Guckel B: CD40-expressing carcinoma cells induce downregulation of CD40 ligand (CD154) and impair T-cell functions. Cancer Res 62: 2052-2057, 2002.

35 Kim H, Kim Y, Bae S, Kong JM, Choi J, Jang M, Choi J, Hong JM, Hwang YI, Kang JS and Lee WJ: Direct Interaction of CD40 on tumor cells with CD40L on T-cells increases the proliferation of tumor cells by enhancing TGF-beta production and Th17 Differentiation. PLoS One 10: e0125742, 2015.

36 Urashima M, Chauhan D, Uchiyama H, Freeman GJ and Anderson KC: CD40 ligand triggered interleukin-6 secretion in multiple myeloma. Blood 85: 1903-1912, 1995.

37 Yamada M, Shiroko T, Kawaguchi Y, Sugiyama Y, Egilmez NK, Chen FA and Bankert RB: CD40-CD40 ligand (CD154) engagement is required but not sufficient for modulating MHC class I, ICAM-1 and FAS expression and proliferation of human non-small cell lung tumors. Int J Cancer 92: 589-599, 2001.

38 Oka M, Iizuka N, Yamamoto K, Gondo T, Abe T, Hazama S, Akitomi Y, Koishihara Y, Ohsugi Y, Ooba Y, Ishihara T and Suzuki T: The influence of interleukin- 6 on the growth of human esophageal cancer cell lines. J Interferon Cytokine Res 16: 10011006, 1996.

39 Chen MF, Chen PT, Lu MS, Lin PY, Chen WC and Lee KD: IL6 expression predicts treatment response and outcome in squamous cell carcinoma of the esophagus. Mol Cancer 12: 26, 2013.

40 Leu CM, Wong FH, Chang C, Huang SF and Hu CP: Interleukin-6 acts as an antiapoptotic factor in human esophageal carcinoma cells through the activation of both STAT3 and mitogen-activated protein kinase pathways. Oncogene 22: 78097818, 2003
Received July 18, 2016

Revised August 3, 2016

Accepted August 5, 2016 